\title{
Correspondence
}

\section{In vitro fertilisation and moral equivalence}

SIR

May I correct a small mistake in your otherwise excellent editorial on in vitro fertilisation in the December issue?

In the context of a discussion as to what 'establishes moral equivalence' you attribute to me the position that moral equivalence is established by the development of sentience, or the ability to experience pain or suffering. You then go on to contrast this with Tooley's position that it is self-awareness which is necessary.

The problem is that to talk of 'moral equivalence' is not especially meaningful unless we ask 'moral equivalence for what purpose?' I certainly hold that if it is the infliction of suffering, or the provision of pleasure, that we are talking about, the capacity for suffering or for pleasure is the criterion which establishes moral equivalence. That is why I emphasised this criterion in my book Animal Liberation. In that work, as I stated in the first chapter, I was concerned with the infliction of pain and suffering on animals. I did not discuss the wrongness of killing, where that is distinct from the infliction of pain and suffering.

If we are talking, however, of taking life, then I do not hold that the capacity for pleasure or pain establishes moral equivalence. I turned to this issue in my later book, Practical Ethics, and there I ended up supporting a position very like Tooley's. It is, other things being equal, a much more serious matter to take the life of a self-conscious being than to take the life of a being without any selfawareness. This is because self-conscious beings have desires for the future which are cut off when they are killed. Beings which are sentient without being self-conscious cannot have a sense of their own future in the same way and so to kill them is not to end their hopes for the future.

In the context of embryos and fetuses, the upshot of all this is that if we are considering research on an embryo or fetus, and the research might be painful (if the embryo or fetus can feel pain) then sentience is sufficient. If the fetus might be sentient, we should treat it as if its pain mattered just as much - or was morally equivalent to - the pain of any other human. If, on the other hand, it is a matter of the painless termination of the life of the fetus, the fact that the fetus is sentient is not enough to make it morally equivalent to a normal human being.

It is true that this position conflicts with widely held views (widely held in the West, anyway) about the moral status of infants. I do not regard this as a knockdown objection, but I must leave the discussion of this point for another occasion.

PETER SINGER

Centre for human bioethics, Monash University, Clayton, Victoria, Australia

Certainly Animal Liberation was the book referred to in the editorial, and assertions such as 'so the limit of sentience (using the term as a convenient if not strictly accurate shorthand for the capacity to suffer and/or experience enjoyment) is the only defensible boundary of concern for the interests of others' (Animal Liberation page 9, emphasis added) resulted in the attribution to Professor Singer of a 'moral-equivalence starts-with-sentience-position'. Editorial apologies however to Professor Singer for not presenting his views as he himself presents them in his later book Practical Ethics and in the letter above.

EDITOR

\section{Brain death}

SIR

In his review of Medicine and Moral Philosophy, David Lamb objected to its essays on brain death, including one by Dr Michael Green and myself. The issues are still important and his remarks deserve a reply.

We argued for a negative thesis, ie $\overrightarrow{0}$ that the whole-brain conception of $\stackrel{\infty}{\perp}$ death is terminally confused, and for a positive thesis concerning a conception of death involving cognitive function.

As Lamb correctly notes, a key point in the negative argument is that the brain stem ought to be regarded as just one more replaceable body part. No 'artificial brain stem' is now available as such, but, we argued, the combined efforts of the resources and personnel in the intensive care unit constitute the equivalent. We now have, in effect, a substitute for the brain stem, though we know from the rapid deterioration of brain-stem-dead patients that the substitute is imperfect.

Lamb, citing the recent report of the President's Commission for the Study of Ethical Problems in Medicine, insists that most of the brain stem's functions are not replaced. But the functions mentioned by the Commission are not $N$ important. Temperature regulation, blood pressure, respiration, digestion, even embryological development con- $\omega$ tinue in the brain-stem-dead body if $\sigma$ suitably maintained. The few reflexes 0 and spontaneous movements which cannot occur are not the stuff whose absence marks the absence of life. The significance of brain stem death is its dashing all hope of any real recovery rather than in any radical deterioration in the well-maintained occupant of an intensive care unit.

Lamb's objection to our positive thesis is not entirely clear. He raises the important question of what it is that dies when the plug is pulled on an already- 